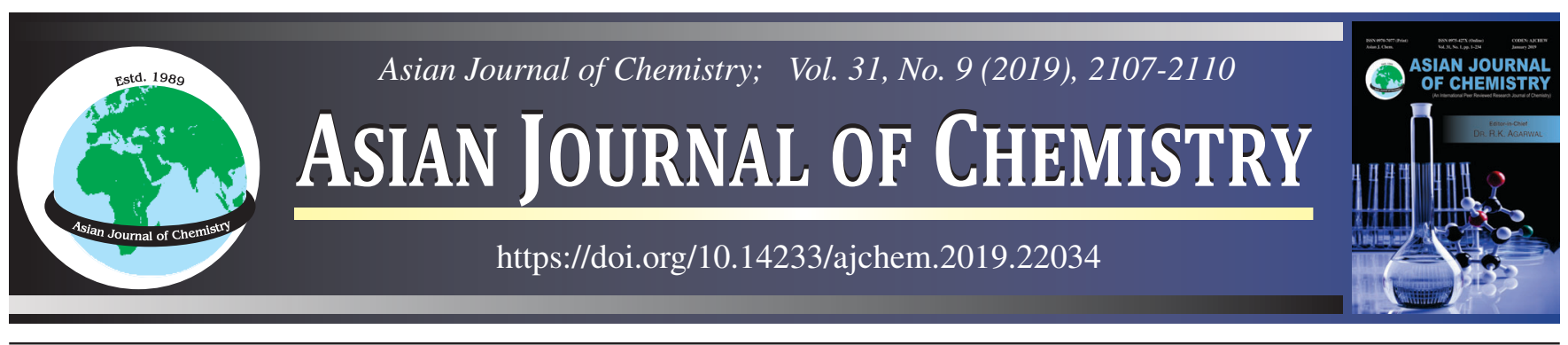

\title{
Evaluation of Nitroxide Radical Catalyst Activity in C-H Activation Step of the Oxidative Coupling between 9,10-Dihydroacridine and Nitromethane
}

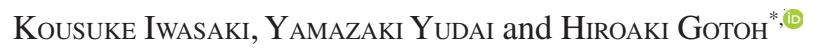

Department of Advanced Materials Chemistry, Yokohama National University, 79-5 Tokiwadai, Hodogaya-ku, Yokohama 240-8501, Japan

*Corresponding author: Fax: +81 45 3393964; Tel: +81 45 3393964, E-mail: gotoh-hiroaki-yw@ynu.ac.jp
Organocatalysts have been the subject of intense research effort because of their low toxicity, facile handling, and eco-friendly characteristics. Recently, the development of C-H activation reaction using organocatalysts has also been studied. Herein, we report the studies on the oxidative coupling of 9,10-dihydroacridine and nitromethane using a series of stable radicals. tert-Butyl(10-phenyl-9-anthryl)nitroxide was found to be an optimal catalyst for the coupling reaction.

| Keywords: C-H activation, Nitroxide radical, Organocatalyst, Air oxidation, Acridine.

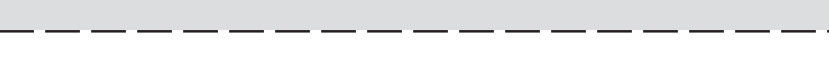

\section{INTRODUCTION}

Activation of $\mathrm{C}-\mathrm{H}$ bond is an environmentally friendly and atom efficient process, attracted growing attention [1]. In terms of $\mathrm{C}-\mathrm{H}$ activation, while transition metals were traditionally required, extensive works to develop the efficient $\mathrm{C}-\mathrm{H}$ activation procedures using organocatalysts [2-7] has recently been explored [8]. For example, compounds such as 2,2-dichloro5,6-dicyanobenzoquinone (DDQ) [9], phenyliodonium diacetate (PIDA) [10] and methanesulfonic acid [11] have been reported as organocatalysts.

In the experiments of $\mathrm{C}-\mathrm{H}$ activation using the nitroxide radical, pioneering work was carried out by Ishii group [12] using $\mathrm{N}$-hydroxyphthalimide (NHPI) as the catalyst. This reaction could be initiated by phthalimide- $N$-oxyl radical (PINO) generated in situ from the oxidation of NHPI by $\mathrm{Co}(\mathrm{acac})_{2} / \mathrm{O}_{2}$. In addition, (2,2,6,6-tetramethylpiperidin-1yl)oxyl (TEMPO) has also been used effectively for this reaction [4-6,13-16], with a number of reports claiming that a combination of TEMPO with transition metals can be used for C-C bond formation $[3,17]$. However, examples of direct oxidative $\mathrm{C}-\mathrm{C}$ bond formation using catalytic amounts of TEMPO are few [3], as due to its low reactivity, its reoxidation efficiency is poor. Although the reaction with TEMPO shows unique and different reactivity to PINO, it has not yet been studied in detail. If stable nitroxide radical (e.g., TEMPO) can be readily oxidized through oxygen in air by a novel molecular design of functional nitroxides or finding optimal experimental conditions for reoxidation, oxidative coupling reaction using nitroxide radicals can be applied widely.

A number of alternative synthetic and commercially available nitroxide radicals are known besides PINO and TEMPO (Fig. 1). For example, Iwabuchi et al. [18] reported the novel nitroxide radical (2-azaadamantane $\mathrm{N}$-oxyl) (AZADO) as a catalyst for alcohol oxidation. In addition, Kanai et al. [19] reported that the combination of a less sterically demanding and electron-deficient novel N-oxyl radical (keto-ABNO, azabicyclo[3.3.1]nonan-3-one- $N$-oxyl) with a copper(I) salt gives high catalytic activity in the aerobic oxidation of amines to imines followed by C-C bond-formation [19]. Our developed (BPAN; tert-butyl(10-phenyl-9-anthryl)nitroxide) [20] is a novel functional nitroxyl radical with radical trapping ability and persistent stability which was found to exhibit less steric hindrance than TEMPO and could easily reoxidized in air. In addition to general purpose nitroxide radicals, (2-phenyl-4,4,5,5tetramethylimidazoline-1-oxyl-3-oxide) (PTIO) [21], (4-oxo2,2,6,6-tetramethyl-1-piperidinyloxy) (4-oxo-TEMPO) [22] and 3-carboxylproxyl (3-CP) [23], Fremy's salt (potassium nitrosodisulfonate) [24] are commercially available ones since nitroxide radical was discovered in 1845 . Other stable radicals,

This is an open access journal, and articles are distributed under the terms of the Attribution 4.0 International (CC BY 4.0) License. This license lets others distribute, remix, tweak, and build upon your work, even commercially, as long as they credit the author for the original creation. You must give appropriate credit, provide a link to the license, and indicate if changes were made. 


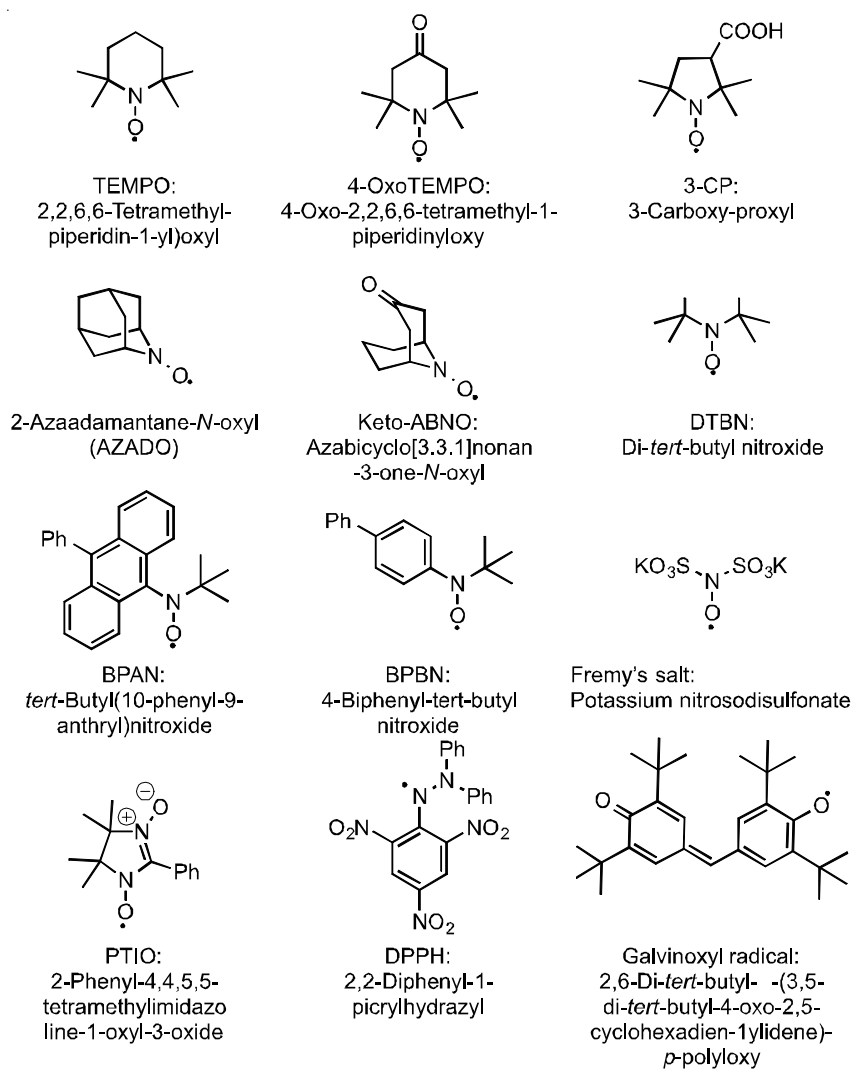

Fig. 1. Structures of the radical catalysts

which do not have nitroxyl group are also known, such as nitrogen centered radical 2,2-diphenyl-1-picrylhydrazyl (DPPH) [25] and oxygen radical galvinoxyl (2,6-di-tert-butyl- $\alpha$-(3,5-di-tertbutyl-4-oxo-2,5-cyclohexadien-1-ylidene)-p-polyloxy) [26].

We herein report studies with regard to the catalytic effectiveness of stable organic radicals for $\mathrm{C}-\mathrm{H}$ activation in the oxidative coupling process. Comparing the characteristic features of the stable organic catalysts used in the model oxidative coupling reactions with 9,10-dihydroacridine will allow us to evaluate the essential factors for enhancing catalytic activity and synthetic yields.

\section{EXPERIMENTAL}

General procedure: 10-Methyl-9,10-dihydroacridine (78.0 mg, $0.4 \mathrm{mmol})$ and BPAN $(6.8 \mathrm{mg}, 0.02 \mathrm{mmol})$ were placed in a Schlenk tube and $\mathrm{CH}_{3} \mathrm{NO}_{2}(1.0 \mathrm{~mL})$ was added. The reaction mixture was stirred at $60^{\circ} \mathrm{C}$ in oxygen atmosphere (1 atm.). After $20 \mathrm{~h}$ stirring, the solvent was removed and the residue was purified by silica gel column chromatography (ethyl acetate/hexane::1:9) to afford the desired product (94.6 $\mathrm{mg}, 0.372 \mathrm{mmol}, 93 \%$ ).

\section{RESULTS AND DISCUSSION}

The catalytic activities of the stable radicals were evaluated on the basis of the obtained yields and experimental conditions. The results were summarized in Table-1. The reaction was carried out in the presence of nitromethane under an oxygen atmosphere, using $5 \mathrm{~mol} \%$ radical catalysts and 1 equiv. of 9,10-dihydroacridine. In the experiment where TEMPO was used (entry 1), similar product yields were achieved to those
TABLE-1

EFFECT OF CATALYST ON THE OXIDATIVE COUPLING OF NITROMETHANE AND THE 9,10-DIHYDROACRIDINE ${ }^{a}$

\begin{tabular}{clcccc}
\hline Entry & \multicolumn{1}{c}{ Catalyst } & $\begin{array}{c}\text { Time } \\
(\mathrm{h})\end{array}$ & $\begin{array}{c}\text { Catalyst } \\
\text { loading }\end{array}$ & $\begin{array}{c}\text { Atmos- } \\
\text { phere }\end{array}$ & $\begin{array}{c}\text { Yield } \\
(\%)\end{array}$ \\
\hline 1 & TEMPO & 20 & 5 & $\mathrm{O}_{2}$ & 65 \\
2 & 4-oxo-TEMPO & 20 & 5 & $\mathrm{O}_{2}$ & 50 \\
3 & 3-CP & 20 & 5 & $\mathrm{O}_{2}$ & 10 \\
4 & AZADO & 20 & 5 & $\mathrm{O}_{2}$ & 19 \\
5 & keto-ABNO & 20 & 5 & $\mathrm{O}_{2}$ & 12 \\
6 & DTBN & 20 & 5 & $\mathrm{O}_{2}$ & 2 \\
7 & BPAN & 20 & 5 & $\mathrm{O}_{2}$ & 93 \\
8 & BPBN & 20 & 5 & $\mathrm{O}_{2}$ & 53 \\
9 & Fremy's salt & 20 & 5 & $\mathrm{O}_{2}$ & 7 \\
10 & PTIO & 20 & 5 & $\mathrm{O}_{2}$ & 43 \\
11 & DPPH & 20 & 5 & $\mathrm{O}_{2}$ & 6 \\
12 & Galvinoxyl radical & 20 & 5 & $\mathrm{O}_{2}$ & 20 \\
13 & BPAN & 48 & 2 & $\mathrm{O}_{2}$ & 92 \\
14 & BPAN & 96 & 1 & $\mathrm{O}_{2}$ & 87 \\
15 & BPAN & 120 & 0.5 & $\mathrm{O}_{2}$ & 66 \\
16 & BPAN & 20 & 10 & $\mathrm{Air}^{2}$ & 75 \\
17 & BPAN & 72 & 5 & $\mathrm{Air}^{2}$ & 53 \\
18 & BPAN-H & 20 & 5 & $\mathrm{O}_{2}$ & 79 \\
\hline
\end{tabular}

${ }^{a}$ Reaction performed using the 9,10 -dihydroacridine on a $0.40 \mathrm{mmol}$ scale at $0.4 \mathrm{M}$ in $\mathrm{CH}_{3} \mathrm{NO}_{2}$ at $60{ }^{\circ} \mathrm{C}$; ${ }^{\text {b Isolated yield. }}$

reported in the literature [3]. In case of galvinoxyl radical (O-centered radical) and DPPH (N-centered radical), lower yields of the product were obtained. In addition, as 3-carboxyl proxyl (3-CP) and Fremy's salt are insoluble at the early stage of the reaction, reactivity was found to be low. In the experiments using AZADO and keto-ABNO, which are intrinsically less hindered nitroxide radicals, lower yields were also observed. In contrast, it should be noticed that BPAN catalyst showed remarkably excellent yield ( $92 \%$ ) with smaller catalyst loading.

Thus, BPAN was selected as catalyst of choice for further experiments. It was found that catalyst loading could be reduced to $2 \mathrm{~mol} \%$ though longer reaction time is necessary. In order to evaluate catalytic activity of BPAN properly, the amount of oxygen required for the reaction should be taken into account as important. As shown the entry 16 in Table-1, oxidative coupling reaction proceeded successfully under air $\left(\sim 21 \% \mathrm{O}_{2}\right)$. In addition, it should be noted that use of a reduced form of catalyst (BPAN-H:N-hydroxylamine) also gave the desired product in good yield suggesting rapid oxidization of BPAN-H in situ.

In order to compare the catalytic activities of radicals shown in Table-1, the amounts of radical catalysts remained in each reaction were determined by ESR when the oxidative coupling reactions were ended. Comparing the amounts of radical catalyst remained, $81 \%$ BPAN and $43 \%$ TEMPO were found to be recovered, thus demonstrating the effectiveness of BPAN as a catalyst.

A proposed catalytic cycle is shown in Fig. 2. Nitroxide radical initiates the reaction with a hydrogen abstraction from the $\mathrm{C}-\mathrm{H}$ bond of the acridine moiety to produce radical and hydroxylamine. The substrate is further oxidized by an additional nitroxide radical to give a cation, which is subsequently attacked by nitromethane to give the desired product. Hydroxy amine can be reoxidized to nitroxide radical by oxygen (air). This mechanism therefore involves a two-step radical-catalyzed 


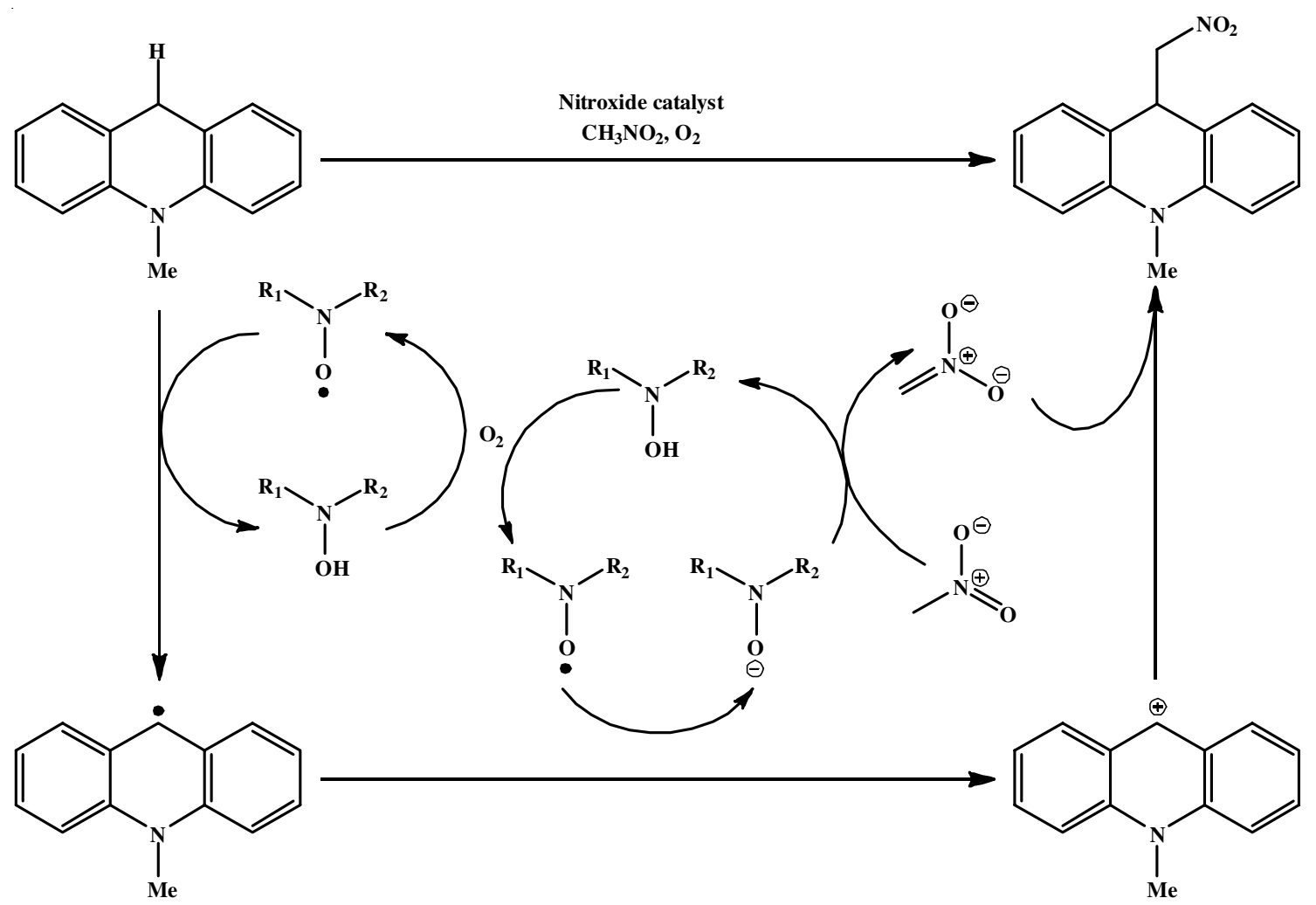

Fig. 2. Proposed mechanism for the coupling reaction between an 9,10-dehydroacridine and nitromethane by nitroxide catalyst under $\mathrm{O}_{2}$ atmosphere

oxidation (hydrogen-transfer and single electron transfer), which is similar to observations from previous literature [13].

The advantageous points of BPAN catalyst are smaller catalytic loading requirement and notably higher reoxidizing feature of the reduced form of BPAN, which facilitates easy regeneration of catalysts and enables oxidative coupling under air. It is believed that abstraction of hydrogen and reoxidation of catalyst are important to the catalytic activity, it is the calculation result ((U)B3LYP/6-31+G**//(U)B3LYP/6-31G*) confirms the relevance from the energy of LUMO energy of nitroxide radical and HOMO of hydroxylamine. Comparison between BPAN and TEMPO, BPAN is lower energy of LUMO (-2.24 ev $v s .-1.55 \mathrm{ev})$, higher energy of hydroxyl amine $(-5.28 \mathrm{ev} v s$. $-6.05 \mathrm{ev})$.

\section{Conclusion}

The oxidative coupling reaction between an 9,10-dihydroacridine and nitromethane issuccessfully investigated. Through present studies, a new insights into this coupling reaction using a series of nitroxide radicals is provided and found that BPAN (tert-butyl(10-phenyl-9-anthryl)nitroxide was the optimal nitroxide based catalyst for this process. Using tert-butyl(10-phenyl9-anthryl)nitroxide) (BPAN) as catalyst, the reaction proceeded even under air, and can therefore be considered ecofriendly. It is further believe that present system can be employed for a range of coupling reactions.

\section{ACKNOWLEDGEMENTS}

This work was financially supported by Grant-in-Aid for Young Scientists (B) from JST (26810055).

\section{CONFLICT OF INTEREST}

The authors declare that there is no conflict of interests regarding the publication of this article.

\section{REFERENCES}

1. C.-J. Li, Acc. Chem. Res., 42, 335 (2009); https://doi.org/10.1021/ar800164n.

2. L. Tebben and A. Studer, Angew. Chem. Int. Ed., 50, 5034 (2011); https://doi.org/10.1002/anie.201002547.

3. B. Zhang, Y. Cui and N. Jiao, Chem. Commun., 48, 4498 (2012); https://doi.org/10.1039/c2cc30684k.

4. B. Han, C. Wang, R.F. Han, W. Yu, X.Y. Duan, R. Fang and X.L. Yang, Chem. Commun., 47, 7818 (2011); https://doi.org/10.1039/c1cc12308d.

5. W. Hu, J.P. Lin, L.R. Song and Y.Q. Long, Org. Lett., 17, 1268 (2015).

6. R. Ding, J.-G. Fu, G.-Q. Xu, B.-F. Sun and G.-Q. Lin, J. Org. Chem., 79, 240 (2014);

https://doi.org/10.1021/jo402419h.

7. C. Galli, P. Gentili and O. Lanzalunga, Angew. Chem. Int. Ed., 47, 4790 (2008); https://doi.org/10.1002/anie.200704292.

8. O. Garcia Mancheno and T. Stopka, Synthesis, 45, 1602 (2013); https://doi.org/10.1055/s-0033-1338480.

9. Z.-L. Wang, X.-L. An, L.-S. Ge, J.-H. Jin, X. Luo and W.-P. Deng, Tetrahedron, 70, 3788 (2014); https://doi.org/10.1016/j.tet.2014.04.021

10. J. Chang, K. Zhao and S. Pan, Tetrahedron Lett., 43, 951 (2002); https://doi.org/10.1016/S0040-4039(01)02302-4.

11. Á. Pintér, A. Sud, D. Sureshkumar and M. Klussmann, Angew. Chem. Int. Ed., 49, 5004 (2010); https://doi.org/10.1002/anie.201000711.

12. Y. Ishii, K. Nakayama, M. Takeno, S. Sakaguchi, T. Iwahama and Y. Nishiyama, J. Org. Chem., 60, 3934 (1995); https://doi.org/10.1021/jo00118a002. 
13. Y.-X. Chen, L.-F. Qian, W. Zhang and B. Han, Angew. Chem. Int. Ed., 47, 9330 (2008); https://doi.org/10.1002/anie.200803381.

14. W.-B. Qin, Q. Chang, Y.-H. Bao, N. Wang, Z.-W. Chen and L.-X. Liu, Org. Biomol. Chem., 10, 8814 (2012); https://doi.org/10.1039/c2ob26390d.

15. K.-U. Schoening, Chim. Oggi, 28, 18 (2010).

16. Q. Cao, L.M. Dornan, L. Rogan, N.L. Hughes and M.J. Muldoon, Chem. Commun., 50, 4524 (2014); https://doi.org/10.1039/C3CC47081D

17. M.S. Maji, T. Pfeifer and A. Studer, Angew. Chem. Int. Ed., 47, 9547 (2008); https://doi.org/10.1002/anie.200804197.

18. M. Shibuya, M. Tomizawa, I. Suzuki and Y. Iwabuchi, J. Am. Chem. Soc., 128, 8412 (2006); https://doi.org/10.1021/ja0620336.
19. T. Sonobe, K. Oisaki and M. Kanai, Chem. Sci., 3, 3249 (2012); https://doi.org/10.1039/c2sc20699d.

20. R. Toba, H. Gotoh and K. Sakakibara, Org. Lett., 16, 3868 (2014); https://doi.org/10.1021/ol501328k

21. E.F. Ullman, J.H. Osiecki, D.G.B. Boocock and R. Darcy, J. Am. Chem. Soc., 94, 7049 (1972); https://doi.org/10.1021/ja00775a031.

22. M.B. Neiman, Y.G. Mamedova and E.G. Rozantsev, Azerbaidzhanskii Khimicheskii Zhurnal, 6, 37 (1962).

23. E.G. Rozantzev and L.A. Krinitzkaya, Tetrahedron, 21, 491 (1965); https://doi.org/10.1016/S0040-4020(01)82219-5.

24. H. Zimmer, D.C. Lankin and S.W. Horgan, Chem. Rev., 71, 229 (1971); https://doi.org/10.1021/cr60270a005.

25. P. Ionita, Chem. Pap., 59, 11 (2005).

26. M.S. Kharasch and B.S. Joshi, J. Org. Chem., 22, 1435 (1957); https://doi.org/10.1021/jo01362a033. 